\title{
Alkaline intracellular pH activates AMPK-mTORC2 signaling to promote cell survival during growth factor limitation
}

Authors: Kazyken, $\mathrm{D}^{1}$, Lentz, $\mathrm{Sl}^{2}$, and Fingar, $\mathrm{DC}^{1}$

\section{Affiliations:}

${ }^{1}$ Department of Cell and Developmental Biology

University of Michigan Medical School

Ann Arbor, Ml 48109-2200

dfingar@umich.edu

734-763-7541

${ }^{*}$ Corresponding author

${ }^{2}$ Division of Metabolism, Endocrinology and Diabetes, Department of Internal Medicine University of Michigan Medical School

Ann Arbor, Ml 48109-2200

The authors declare that they have no conflicts of interest with the contents of this article.

One Sentence Summary: Alkaline intracellular pH activates mTORC2

\begin{abstract}
Abbreviations not defined in the text:
mTORC1, mTOR complex 1; mTORC2, mTOR complex 2; mTORC, mTOR complex; D-PBS, Dulbecco's-phosphate buffered saline; DMEM, Dulbecco's modified eagle medium; HBSS, Hank's balanced salt solution; MEFs, mouse embryonic fibroblasts; $\mathrm{PI} 3 \mathrm{~K}$, phosphatidylinositol 3-kinase; $\mathrm{NH}_{4} \mathrm{Cl}$, ammonium chloride.
\end{abstract}

Character count: $25,846(26,000$ max $)$ 


\section{Abstract}

mTORC2 controls cell metabolism and promotes cell survival, yet its upstream regulation by diverse cellular cues remains poorly defined. While considerable evidence indicates that mTORC1 but not mTORC2 responds dynamically to amino acid levels, several studies reported activation of mTORC2 signaling by amino acids, a paradox that remains unresolved. Following amino acid starvation, we noted that addition of a commercial amino acid solution but not re-feeding with DMEM containing amino acids increased mTORC2 signaling. Interestingly, the $\mathrm{pH}$ of the amino acid solution was $\sim 10$. These key observations enabled us to discover that alkaline intracellular $\mathrm{pH}(\mathrm{pHi})$ represents a previously unknown activator of mTORC2. Using a fluorescent pH-sensitive dye (cSNARF-1-AM) coupled to live-cell imaging, we demonstrate that alkaline extracellular $\mathrm{pH}(\mathrm{pHe})$ increases intracellular $\mathrm{pHi}$, which increases mTORC2 catalytic activity and downstream signaling to Akt. Alkaline pHi also activates AMPK, a sensor of energetic stress. Functionally, alkaline pHi attenuates apoptosis caused by growth factor withdrawal, which requires AMPK in part and $\mathrm{mTOR}$ in full. Collectively, these findings reveal that alkaline $\mathrm{pHi}$ increases AMPK-mTORC2 signaling to promote cell survival during growth factor limitation. As elevated $\mathrm{pHi}$ represents an under-appreciated hallmark of cancer cells, alkaline $\mathrm{pH}$ sensing by AMPK-mTORC2 may contribute to tumorigenesis. 


\section{Introduction}

mTOR (the mechanistic target of rapamycin) comprises the catalytic core of two distinct multiprotein complexes, mTORC1 and mTORC2. These mTORCs sense and integrate diverse extra- and intra-cellular signals derived from hormones, growth factors, nutrients, and energy through distinct downstream substrates to control cell physiology in ways appropriate for biological context (1-5). mTORC1 primarily promotes anabolic cellular processes (e.g., protein, lipid, and nucleotide synthesis) that sustain cell growth and cell proliferation while mTORC2 controls cell metabolism, cell survival, and the actin cytoskeleton (1-5). Not surprisingly, elevated mTORC1 and mTORC2 signaling contribute to pathologic conditions, including tumorigenesis $(4,5)$.

Activation of mTORC1 by the cooperative action of insulin and amino acids has been studied extensively. In response to insulin, activation of the PI3K-Akt-TSC pathway leads to Rheb-GTP mediated activation of $\mathrm{mTORC} 1$ on the surface of lysosomes in a manner that requires sufficient levels of amino acids (4,6-8). Amino acids load RagA/B proteins with GTP, which recruit mTORC1 to lysosomal membranes in proximity to Rheb (8-14). Through an induced proximity mechanism, Rheb-GTP in turn interacts with and activates mTORC1 through conformational changes (15-17). TSC and Rheb represent central signaling nodes at which growth factor and amino acid signals converge to effect mTORC1 regulation (4,6,7). Insulin-PI3K-Akt signaling and amino acid sufficiency are required simultaneously to dissociate TSC from lysosomal membranes and away from Rheb, thus maintaining Rheb-GTP loading (18-20). Our knowledge of upstream pathways and mechanisms controlling mTORC2 activity and downstream signaling lags far behind that of mTORC1, however (4,5). Activation of mTORC2 signaling by hormones and growth factors requires PI3K $(4,5,21)$, and oncogenic Ras interacts with mTORC2 to increase its activity on the plasma membrane $(22,23)$. Curiously, nutrient withdrawal, specifically glutamine or glucose, activates mTORC2 $(24,25)$, and upregulation of the stress sensing protein Sestrin2, which occurs during glutamine deprivation, increases mTORC2 activity $(26,27)$. In addition, our prior work demonstrated that during energetic stress, AMP-activated protein kinase (AMPK) directly activates mTORC2 to promote cell survival (25).

Considerable evidence indicates that amino acids are required for mTORC1 but not mTORC2 signaling (4,5,28-31). Several studies reported paradoxical activation of mTORC2 signaling by amino acid stimulation, however (32-35). The reason for this discrepancy remains unclear. While studying amino acid sensing by $\mathrm{mTORC} 1$, we noted that after amino acid starving cells, addition of a commercial amino acid solution but not re-feeding cells with DMEM containing amino acids activated mTORC2 signaling. Interestingly, we found the $\mathrm{pH}$ of the amino acid solution to be $\sim \mathrm{pH} 10$. When we adjusted the $\mathrm{pH}$ of the amino acid solution to physiological $\mathrm{pH} 7.4$, it failed to increase mTORC2 signaling. These key observations enabled us to discover and demonstrate here that alkaline extracellular $\mathrm{pH}(\mathrm{pHe})$ increases intracellular $\mathrm{pH}(\mathrm{pHi})$, which increases AMPK and mTORC2 signaling to attenuate apoptosis caused by growth factor withdrawal. As elevated pHi represents an under-appreciated hallmark of cancer cells (36- 
38), alkaline $\mathrm{pH}$ sensing by AMPK-mTORC2 may enable growth factor- and nutrient-deprived cancer cells at the core of a growing tumor to evade apoptosis and survive.

\section{Results}

\section{Amino acids at alkaline pH but not physiological pH increase mTORC2 and AMPK signaling}

Researchers in the mTOR field employ diverse methods to amino acid starve and stimulate cells. While studying the mTORC1 response to amino acids, we noted that after amino acid starving cells in DPBS containing dialyzed FBS (dFBS), addition of a commercial amino acid solution increased mTORC2 signaling, as measured by the sensitivity of Akt S473 phosphorylation to the mTOR inhibitor Torin1 (Figure 1A, left). Consistent with Akt S473 phosphorylation promoting and/or stabilizing Akt T308 phosphorylation $(25,39,40)$, the amino acid solution also increased Torin1-sensitive Akt T308 phosphorylation (Figure 1A, left). We obtained similar results in the absence of serum growth factors (i.e., without FBS) (Figure 1A, right). Curiously, amino acid stimulation also increased phosphorylation of AMPK $\alpha$ on its activation loop site (S172) as well as the phosphorylation of mTOR S1261 and ACC S79, direct substrates of AMPK (Figure 1A, left and right) $(25,41,42)$. As expected, amino acids increased S6K1 T389 phosphorylation in a Torin1-sensitive manner, an established readout of mTORC1 signaling (Figure 1A). On their face, these data are consistent with prior reports that amino acids increase mTORC2 (32-35) and AMPK signaling (33).

When we used DMEM to amino acid deprive cells rather than D-PBS, however, addition of the amino acid solution induced a rapid change in DMEM color from orange-red (indicates physiological pH $\sim 7.4$ ) to purple (indicates alkaline $\mathrm{pH}$ ). Indeed, we measured the $\mathrm{pH}$ of the amino acid solution and found it to be $\sim \mathrm{pH} 10$. To carefully compare how alkaline $\mathrm{pH}$ vs. amino acids control mTORC2 signaling, we adjusted the $\mathrm{pH}$ of DMEM lacking or containing amino acids to 7.4 or 8.3. DMEM at pH 8.3 but not 7.4 increased mTORC2 (i.e., Akt P-S473 and P-T308) and AMPK (i.e., mTOR P-S1261; ACC P-S79) signaling regardless of amino acid status in both the presence (Figure 1B, left) and absence (Figure 1B, right) of serum growth factors. As expected, DMEM containing but not lacking amino acids increased mTORC1 signaling (i.e., S6K1 P-T389) regardless of pH (Figure 1B). Upon adjusting the $\mathrm{pH}$ of the amino acid solution, its addition at $\mathrm{pH} 10$ but not 7.4 to cells in D-PBS (+ dFBS) increased mTORC2 and AMPK signaling (Figure 1C). Importantly, our findings confirm those of Tato et al. (32) and Pezze et al. (33), who reported that commercial amino acid solutions added to amino acid starved cells increase mTORC2 signaling. Figure $1 \mathrm{~A}$ (right) replicates the results of Tato et al. using identical amino acid starvation and stimulation conditions (Figure 1A right), while Figure S1A replicates the results of Pezze et al. in which addition of an amino acid solution to $\mathrm{C} 2 \mathrm{C} 12$ myoblasts incubated in HBSS increased mTORC2 signaling. When we controlled for $\mathrm{pH}$, however, addition of the amino acid solution at $\mathrm{pH} 7.4$ to $\mathrm{C} 2 \mathrm{C} 12$ myoblasts amino acid starved in either HBSS (Figure S1A) or DMEM (Figure S1B) failed to increase mTORC2 
signaling. Collectively, these results provide strong evidence that increased $\mathrm{pH}$ - not amino acidsincreases mTORC2 and AMPK signaling.

\section{Alkaline extracellular $\mathrm{pH}(\mathrm{pHi})$ increases mTORC2 catalytic activity and signaling}

We next investigated whether alkaline extracellular $\mathrm{pH}(\mathrm{pHe})$ is sufficient to increase mTORC2 signaling in the absence of any changes in amino acid levels. Re-feeding MEFs cultured in complete media (DMEM with amino acids and FBS) with DMEM at $\mathrm{pH} 8.3$ but not $\mathrm{pH} 7.4$ increased Akt phosphorylation (P-S473 and P-T308) in MEFs (Figure 2A) and HEK293T cells (Figure S2A). These effects were rapid and transient, with maximal phosphorylation of Akt occurring at 5-15 minutes with apparent declines by 30-60 min, possibly because elevated $\mathrm{pH}$ cannot be maintained in these media conditions. As in Figure 1, the activating effect of pHe on Akt phosphorylation was Torin1-sensitive in MEFs (Figure 2B) and HEK293T cells (Figure S2B), thus reflecting mTORC2 signaling. pH dose response experiments $(\mathrm{pH}$ 7.4-9.0) demonstrated that $\mathrm{pH}$ 8.3-8.5 mediated maximal mTORC2 signaling in MEFs (Figure S2C). To test whether alkaline pHe increases mTORC2 intrinsic catalytic activity, we performed mTORC2 in vitro kinase (IVK) assays. We re-fed MEFs with DMEM pH 8.3, immuno-purified mTORC2 by immunoprecipitation of Rictor (a partner protein exclusive to mTORC2), and measured phosphorylation of His-Akt1 by mTORC2 in vitro. Alkaline pHe increased mTORC2 catalytic activity (Figure $2 \mathrm{C}$ ). To increase $\mathrm{pHi}$ by an alternate method, we used $\mathrm{NH}_{4} \mathrm{Cl}$, which increases cytosolic and organellar $\mathrm{pH}$. Indeed, $\mathrm{NH}_{4} \mathrm{Cl}$ increased mTORC2 signaling (Figure 2D). Finally, we used the pharmacologic drug cariporide to lower intracellular $\mathrm{pH}(\mathrm{pHi})$, as in other studies (43-45). Cariporide inhibits $\mathrm{NHEl}, \mathrm{a} \mathrm{H}^{+}-\mathrm{Na}^{+}$antiporter on the plasma membrane that drives proton $\left(\mathrm{H}^{+}\right)$efflux from the cytosol to the extracellular space (43-45). Cariporide blunted the ability of alkaline pHe to increase mTORC2 signaling in MEFs (Figure 2E) and HEK293 cells (Figure S1B). Taken together, these results demonstrate that increased intracellular $(\mathrm{pHi})$ mediates the effect of alkaline extracellular $(\mathrm{pHe})$ on mTORC2 signaling.

\section{Incubation of cells in media at alkaline $\mathrm{pH}$ or containing $\mathrm{NH} 4 \mathrm{Cl}$ increases intracellular $\mathrm{pH}(\mathrm{pHi})$}

We next confirmed that incubation of cells in media at alkaline $\mathrm{pH}$ increases intracellular $\mathrm{pH}(\mathrm{pHi})$. To do so, we used live-cell imaging coupled with a cell-permeable, $\mathrm{pH}$-sensitive fluorescent dye (cSNARF-1-AM) that is capable of measuring changes in intracellular $\mathrm{pH}(\mathrm{pHi})$ between 7 and 8. cSNARF-1-AM undergoes a pH-sensitive shift in fluorescence wavelength emission depending on protonation state. With $488 \mathrm{~nm}$ excitation, peak emission occurs at $580 \mathrm{~nm}$ in the protonated state (more acidic) and $640 \mathrm{~nm}$ in the de-protonated state (more alkaline). Thus, ratiometric imaging (640:580 nm) enables detection of changes in intracellular $\mathrm{pH}$ within the physiological range of normal cells $(\sim \mathrm{pH} 7.2)$ and cancer cells ( pH 7.4-7.6) (37,46). MEFs were pre-loaded with cSNARF-1-AM and then re-fed with complete DMEM at pH 7.4 for 10 minutes followed by re-feeding with media at $\mathrm{pH} 8.3$ for 10 minutes. 
Visualization of the acquired pseudo-colored ratiometric images (640:580 $\mathrm{nm})$ and quantitation of the signal ratios revealed a striking and significant increase in intracellular $\mathrm{pH}$ (Figure $3 \mathrm{~A})$. Addition of $\mathrm{NH}_{4} \mathrm{Cl}$ to DMEM ( $\mathrm{pH} 7.4$ ) also increased pHi (Figure 3B. These results confirm that alkaline extracellular increases intracellular $\mathrm{pH}$, consistent with other studies $(47,48)$.

\section{AMPK promotes mTORC2 signaling and cell survival in response to alkaline intracellular $\mathrm{pH}(\mathrm{pHi})$}

Our prior work demonstrated that energetic stress increases mTORC2 catalytic activity and signaling directly through AMPK mediated phosphorylation of mTOR and mTORC2 partner proteins (e.g., Rictor) (25). As the AMPK-mTORC2 axis responds to energetic stress, we speculated that it may also respond to alkaline $\mathrm{pH}$ stress. We therefore compared the ability of alkaline pHe to increase mTORC2 signaling in wild type and AMPK $\alpha 1 / \alpha 2$ double knockout MEFs (i.e., AMPK DKO). When MEFs incubated in D-PBS/ dFBS were stimulated with the amino acid solution at $\mathrm{pH} 10$ or re-fed with D-PBS/ dFBS adjusted to $\mathrm{pH} 9.5$ (the $\mathrm{pH}$ of D-PBS/ dFBS after addition of the $\mathrm{pH} 10$ amino acid solution to 1x), we found that alkaline pHe increased mTORC2 signaling in a manner partly dependent on AMPK (Figures 4A, 4B). As expected, AMPK double knockout abrogated AMPK signaling (AMPK P-S172; mTOR P-S1261; Raptor P-S792) (Figures 4A, 4B). Alkaline pHi was also sufficient to increase mTORC2 signaling in a manner partly dependent on AMPK in cells cultured in complete media (i.e., DMEM/ FBS) (Figure 4C). These results indicate that alkaline pHi increases mTORC2 signaling through AMPK and another unknown signal(s).

Cell survival requires sufficient levels of growth factors (49), and our recent work demonstrated that AMPK-mTORC2 signaling promotes cell survival in response to acute energetic stress (25). We therefore tested the hypothesis that elevated pHi protects against apoptosis during growth factor limitation, a setting common for growing tumors. We therefore serum-starved MEFs overnight (16 hr.) in DMEM and then re-fed the cells with either complete media (i.e., with FBS) or serum-free media (i.e., without FBS) for an additional $3 \mathrm{hrs}$. As expected, cells maintained in serum-free media for the full 19 hrs. displayed increased apoptosis relative to those rescued with complete media for the last $3 \mathrm{hrs}$., as monitored by blotting for cleaved caspase 3 (cCas3) and cleaved Parp (cParp) (Figure 4D). Consistent with our hypothesis that alkaline pHi protects against apoptosis, re-feeding MEFs with serum-free media whose $\mathrm{pH}$ had been adjusted to 7.8 using sodium bicarbonate rather than $\mathrm{NaOH}$ (which maintains the $\mathrm{pH}$ of DMEM for longer periods of time) suppressed apoptosis relative to serum-free re-feeding at $\mathrm{pH} 7.4$ in a Torin1 sensitive manner (Figure 4D). While prolonged alkaline pHi (i.e., 3 hr.) could not maintain Akt S473 phosphorylation, it maintained inhibitory phosphorylation of the Akt substrate and pro-apoptotic protein BAD (Figure 4D). Consistent with our hypothesis that AMPK is required for alkaline pHi to protect against apoptosis, double knockout of AMPK $\alpha 1 / \alpha 2$ partially suppressed the ability of serum-free media at alkaline $\mathrm{pH} 7.8$ to attenuate apoptosis caused by growth factor withdrawal (Figures 4E; S3). 


\section{Discussion}

This study identifies alkaline intracellular $\mathrm{pH}(\mathrm{pHi})$ as a previously unrecognized activator of AMPK and mTORC2 that attenuates apoptosis during growth factor limitation (Figure 4F). As AMPK promotes mTORC2 signaling and cell survival mediated by alkaline intracellular $\mathrm{pH}(\mathrm{pHi})$ in part rather than in full, other signals (?) cooperate with AMPK to activate mTORC2 in response to alkaline $\mathrm{pHi}$. It is important to note that a recent study found that alkaline pHi increased Akt (S473) phosphorylation, although mechanistic details were not defined (47). We speculate that prior studies reporting activation of AMPK and mTORC2 signaling by amino acids (32-35) likely mistook an increase in pHi for an increase in amino acid levels. In fact, Tato et al. concluded that amino acids selectively activate mTORC2 signaling depending on the method of amino acid starvation and stimulation employed (32) (i.e., amino acids activated mTORC2 signaling in amino acid starved cells in response to addition of a commercial amino acid solution but not upon re-feeding with amino acid replete DMEM). By controlling for the $\mathrm{pH}$ of the amino acid solution or using DMEM lacking or containing amino acids, our results reveal that alkaline pHi- not amino acids- increases mTORC2 signaling, thus correcting a misconception in the mTOR field.

Dysregulated $\mathrm{pH}$ represents an under-appreciated hallmark of cancer cells, which display a reversal in the $\mathrm{pH}$ gradient controlled by altered proton $\left(\mathrm{H}^{+}\right)$flux (i.e., elevated intracellular $\mathrm{pHi}$ and decreased extracellular pHe, the reverse of normal cells) $(36-38,45,46)$. Functionally, dysregulated $\mathrm{pH}$ dynamics modifies cancer cell behaviors, including proliferation, survival, metabolic adaptation, migration, and metastasis. Changes in $\mathrm{pHi}$ control the structure and function of $\mathrm{pH}$-sensitive proteins (aka, pH-sensors) through protonation/ de-protonation, a posttranslational modification akin to phosphorylation, ubiquitination, etc. $(36-38,46)$. Documented $\mathrm{pH}$-sensors with recurring charge-changing mutations (e.g., Arg to His) include p53, EGF-receptor, Ras-GRP1, and $\beta$-catenin (50-53). Elevated activity of several plasma membrane ion exchangers, including the $\mathrm{Na}^{+}-\mathrm{H}^{+}$exchanger $\mathrm{NHE}$, contributes to increased $\mathrm{pHi}$ and correlates with tumor initiation, progression, and metastasis $(37,45)$. Indeed, increased $\mathrm{H}^{+}$efflux contributes to transformed cell behaviors mediated by oncogenic Ras, as demonstrated in human mammary cells and a Drosophila model in vivo (54). By identifying alkaline pHi as an activator of AMPK-mTORC2 signaling that attenuates apoptosis caused by growth factor withdrawal, our work suggests that the AMPK-mTORC2 axis may drive tumorigenesis in response to dysregulated $\mathrm{pH}$ dynamics by enabling growth factor-, nutrient-, and oxygen-deprived cancer cells at the core of a growing tumor to survive. Such a role is consistent with the paradoxical role of AMPK as a tumor promoter in certain contexts (despite its established role as a tumor suppressor) and the newfound role for AMPK-mTORC2 signaling in cell survival during energetic stress (25,55-60). More broadly, our results suggest that the AMPK-mTORC2 axis senses diverse types of cellular stress, which likely rewires cell metabolism to help cells adapt and survive. In the future, it will be important to identify the $\mathrm{pH}-$ sensors that transduce signals to AMPK and mTORC2. 


\section{Experimental Procedures}

\section{Cell Culture}

Cell lines (MEFs; HEK293T; C2C12) were cultured in DMEM containing high glucose [4.5 g/liter], glutamine [584 mg/liter] and sodium pyruvate [110 mg/liter] (Life Technologies \#11995-065) supplemented with 10\% fetal bovine serum (FBS) (Life Technologies \#10347-028) and incubated at $37^{\circ} \mathrm{C}$ in a humidified atmosphere with $7.5 \% \mathrm{CO}_{2}$. To effect amino acid (AA) starvation, cells were cultured in either D-PBS (which contains [1 g/L] D-glucose) (Life Technologies \#14287-080) or AA-free DMEM (US Biologicals \#D9800-13) without or with 10\% dialyzed FBS (Life Technologies \#A33820-01) for 50 minutes. To effect serum-starvation, cells were cultured in DMEM containing $20 \mathrm{mM}$ Hepes $\mathrm{pH} 7.2$ for $\sim 16 \mathrm{hr}$. overnight. Cells were amino acid (AA) stimulated in two ways: 1) An amino acid solution (RPMI 1640 Amino Acid Solution [50x] (Sigma \# R7131) supplemented with L-glutamine (Sigma \# G8540) was added to cells in AA-free media to a final concentration of $1 x(\sim$ concentration in RPMI) or $5 x(\sim$ concentration in DMEM). The pH of the amino acid solution was either not adjusted ( pH 10) or adjusted to $\mathrm{pH} 7.4$ with $1 \mathrm{~N} \mathrm{HCl}$; or 2) Cells were re-fed with AA-replete DMEM after incubation in AA-free DMEM. To treat cells at various alkaline extracellular pHs acutely, the $\mathrm{pH}$ of D-PBS or DMEM was adjusted with $\mathrm{NaOH}$. To stably maintain DMEM at alkaline $\mathrm{pH}$ (i.e., $\mathrm{pH} 7.8$ ), the $\mathrm{NaHCO}_{3}$ concentration was increased from $44 \mathrm{mM}$ to $120 \mathrm{mM}$ by directly dissolving in $\mathrm{NaHCO}_{3}$ followed by filter sterilization and equilibration overnight in an incubator at $7.5 \% \mathrm{CO}_{2}$, as described (48).

\section{Live-cell imaging of cSNARF-1-AM}

MEFs were plated in 8-well cover glass bottom chambers (Lab-tek \#155409) and loaded with cSNARF-1AM $\left[10 \mu \mathrm{M}\right.$ ] (Thermo Fisher \#C1272), a fluorescent $\mathrm{pH}$-sensitive dye, for 30 min at $37^{\circ} \mathrm{C}$ in serum-free DMEM. The cells were then rinsed with serum-free DMEM and re-fed with DMEM/ FBS [10\%] pH 7.4. Livecell imaging (0-10 min) of cells cultured in DMEM/ FBS pH 7.4 or 8.3 was performed using a Nikon A1 confocal microscope equipped with a stage-top incubator that maintains temperature and $\mathrm{CO}_{2}$. Images were acquired using a 40x oil objective (1.3 NA) at a resolution of $1024 \times 1024$ and an optical thickness of $1.18 \mu \mathrm{m}$ (confocal aperture set at 3 airy units). cSNARF1-AM signal was excited with an argon laser at $488 \mathrm{~nm}$ and images sets were collected simultaneously in two emission band pass filters at 553-618 nm (for $580 \mathrm{~nm}$ ) and 663-738 nm (for $640 \mathrm{~nm}$ ). Nikon Elements software was used to create and pseudo-color the $640: 580 \mathrm{~nm}$ ratiometric images with values ranging from 0 (violet) to 2.0 (red). MetaMorph software was used to quantify the ratiometric images by measuring the average ratio of a region of interest within one cell, and 25 cells per image were quantified. A change in the 640:580 nm ratio and accompanying pseudo-colored image reflects a change in intracellular $\mathrm{pH}(\mathrm{pHi})$.

\section{Acknowledgments}

We thank Drs. B. Viollet (Inserm, Paris, France) and R. Shaw (Salk Institute, San Diego, CA) for sharing immortalized wild-type and AMPK $\alpha 1 / \alpha 2$ DKO MEFs. We also thank Dr. P. Goforth for advice with $\mathrm{pH}$ sensing dyes. This work was supported by a grant from the NIH (R01 GM-137577) (to DCF) and by the Michigan Diabetes Research Center (MDRC) (NIH-NIDDK; \#P30 DK020572).

Supplemental Information. See the Supplement for additional a) Experimental Procedures including materials, antibodies, drug treatments, cell lysis, immunoprecipitation, and western blotting, mTORC2 in vitro kinase assays, statistical analysis, and image editing; and b) Supporting Figures S1-S3. 


\section{References}

1. Huang, K., and Fingar, D. C. (2014) Growing knowledge of the mTOR signaling network. Semin Cell Dev Biol 36, 79-90

2. Gomes, A. P., and Blenis, J. (2015) A nexus for cellular homeostasis: the interplay between metabolic and signal transduction pathways. Curr Opin Biotechnol 34, 110-117

3. Ben-Sahra, I., and Manning, B. D. (2017) mTORC1 signaling and the metabolic control of cell growth. Curr Opin Cell Biol 45, 72-82

4. Liu, G. Y., and Sabatini, D. M. (2020) mTOR at the nexus of nutrition, growth, ageing and disease. Nat Rev Mol Cell Biol

5. Szwed, A., Kim, E., and Jacinto, E. (2021) Regulation and metabolic functions of mTORC1 and mTORC2. Physiol Rev

6. Manning, B. D., and Toker, A. (2017) AKT/PKB Signaling: Navigating the Network. Cell 169, 381405

7. Hoxhaj, G., and Manning, B. D. (2020) The PI3K-AKT network at the interface of oncogenic signalling and cancer metabolism. Nat Rev Cancer 20, 74-88

8. Lawrence, R. E., and Zoncu, R. (2019) The lysosome as a cellular centre for signalling, metabolism and quality control. Nat Cell Biol 21, 133-142

9. Sancak, Y., Peterson, T. R., Shaul, Y. D., Lindquist, R. A., Thoreen, C. C., Bar-Peled, L., and Sabatini, D. M. (2008) The Rag GTPases bind raptor and mediate amino acid signaling to mTORC1. Science 320, 1496-1501

10. Sancak, Y., Bar-Peled, L., Zoncu, R., Markhard, A. L., Nada, S., and Sabatini, D. M. (2010) Ragulator-Rag complex targets mTORC1 to the lysosomal surface and is necessary for its activation by amino acids. Cell 141, 290-303

11. Kim, E., Goraksha-Hicks, P., Li, L., Neufeld, T. P., and Guan, K. L. (2008) Regulation of TORC1 by Rag GTPases in nutrient response. Nat Cell Biol 10, 935-945

12. Wolfson, R. L., and Sabatini, D. M. (2017) The Dawn of the Age of Amino Acid Sensors for the mTORC1 Pathway. Cell Metab 26, 301-309

13. Gonzalez, A., and Hall, M. N. (2017) Nutrient sensing and TOR signaling in yeast and mammals. EMBO J 36, 397-408

14. Kim, J., and Guan, K. L. (2019) mTOR as a central hub of nutrient signalling and cell growth. Nat Cell Biol 21, 63-71

15. Long, X., Lin, Y., Ortiz-Vega, S., Yonezawa, K., and Avruch, J. (2005) Rheb binds and regulates the mTOR kinase. Curr Biol 15, 702-713

16. Long, X., Ortiz-Vega, S., Lin, Y., and Avruch, J. (2005) Rheb binding to mammalian target of rapamycin (mTOR) is regulated by amino acid sufficiency. $J$ Biol Chem 280, 23433-23436

17. Yang, H., Jiang, X., Li, B., Yang, H. J., Miller, M., Yang, A., Dhar, A., and Pavletich, N. P. (2017) Mechanisms of mTORC1 activation by RHEB and inhibition by PRAS40. Nature 552, 368-373

18. Menon, S., Dibble, C. C., Talbott, G., Hoxhaj, G., Valvezan, A. J., Takahashi, H., Cantley, L. C., and Manning, B. D. (2014) Spatial control of the TSC complex integrates insulin and nutrient regulation of $\mathrm{mTORC} 1$ at the lysosome. Cell 156, 771-785

19. Demetriades, C., Doumpas, N., and Teleman, A. A. (2014) Regulation of TORC1 in response to amino acid starvation via lysosomal recruitment of TSC2. Cell 156, 786-799

20. Demetriades, C., Plescher, M., and Teleman, A. A. (2016) Lysosomal recruitment of TSC2 is a universal response to cellular stress. Nature communications 7, 10662

21. Liu, P., Gan, W., Chin, Y. R., Ogura, K., Guo, J., Zhang, J., Wang, B., Blenis, J., Cantley, L. C., Toker, A., Su, B., and Wei, W. (2015) Ptdlns(3,4,5)P3-Dependent Activation of the mTORC2 Kinase Complex. Cancer Discov 5, 1194-1209

22. Kovalski, J. R., Bhaduri, A., Zehnder, A. M., Neela, P. H., Che, Y., Wozniak, G. G., and Khavari, P. A. (2019) The Functional Proximal Proteome of Oncogenic Ras Includes mTORC2. Mol Cell 73, 830-844 e812

23. Senoo, H., Kamimura, Y., Kimura, R., Nakajima, A., Sawai, S., Sesaki, H., and lijima, M. (2019) Phosphorylated Rho-GDP directly activates mTORC2 kinase towards AKT through dimerization with Ras-GTP to regulate cell migration. Nat Cell Biol 21, 867-878 
24. Moloughney, J. G., Kim, P. K., Vega-Cotto, N. M., Wu, C. C., Zhang, S., Adlam, M., Lynch, T., Chou, P. C., Rabinowitz, J. D., Werlen, G., and Jacinto, E. (2016) mTORC2 Responds to Glutamine Catabolite Levels to Modulate the Hexosamine Biosynthesis Enzyme GFAT1. Mol Cell 63, 811-826

25. Kazyken, D., Magnuson, B., Bodur, C., Acosta-Jaquez, H. A., Zhang, D., Tong, X., Barnes, T. M., Steinl, G. K., Patterson, N. E., Altheim, C. H., Sharma, N., Inoki, K., Cartee, G. D., Bridges, D., Yin, L., Riddle, S. M., and Fingar, D. C. (2019) AMPK directly activates mTORC2 to promote cell survival during acute energetic stress. Sci Signal 12

26. Byun, J. K., Choi, Y. K., Kim, J. H., Jeong, J. Y., Jeon, H. J., Kim, M. K., Hwang, I., Lee, S. Y., Lee, Y. M., Lee, I. K., and Park, K. G. (2017) A Positive Feedback Loop between Sestrin2 and mTORC2 Is Required for the Survival of Glutamine-Depleted Lung Cancer Cells. Cell reports 20, 586-599

27. Kowalsky, A. H., Namkoong, S., Mettetal, E., Park, H. W., Kazyken, D., Fingar, D. C., and Lee, J. H. (2020) The GATOR2-mTORC2 axis mediates Sestrin2-induced AKT Ser/Thr kinase activation. J Biol Chem 295, 1769-1780

28. Jacinto, E., Facchinetti, V., Liu, D., Soto, N., Wei, S., Jung, S. Y., Huang, Q., Qin, J., and Su, B. (2006) SIN1/MIP1 maintains rictor-mTOR complex integrity and regulates Akt phosphorylation and substrate specificity. Cell 127, 125-137

29. Guertin, D. A., Stevens, D. M., Thoreen, C. C., Burds, A. A., Kalaany, N. Y., Moffat, J., Brown, M., Fitzgerald, K. J., and Sabatini, D. M. (2006) Ablation in mice of the mTORC components raptor, rictor, or mLST8 reveals that $\mathrm{mTORC2}$ is required for signaling to Akt-FOXO and PKCalpha, but not S6K1. Dev Cell 11, 859-871

30. Chantranupong, L., Wolfson, R. L., Orozco, J. M., Saxton, R. A., Scaria, S. M., Bar-Peled, L., Spooner, E., Isasa, M., Gygi, S. P., and Sabatini, D. M. (2014) The Sestrins interact with GATOR2 to negatively regulate the amino-acid-sensing pathway upstream of mTORC1. Cell reports 9, 1-8

31. Yang, G., Murashige, D. S., Humphrey, S. J., and James, D. E. (2015) A Positive Feedback Loop between Akt and mTORC2 via SIN1 Phosphorylation. Cell reports 12, 937-943

32. Tato, I., Bartrons, R., Ventura, F., and Rosa, J. L. (2011) Amino acids activate mammalian target of rapamycin complex 2 (mTORC2) via PI3K/Akt signaling. J Biol Chem 286, 6128-6142

33. Dalle Pezze, P., Ruf, S., Sonntag, A. G., Langelaar-Makkinje, M., Hall, P., Heberle, A. M., Razquin Navas, P., van Eunen, K., Tolle, R. C., Schwarz, J. J., Wiese, H., Warscheid, B., Deitersen, J., Stork, B., Fassler, E., Schauble, S., Hahn, U., Horvatovich, P., Shanley, D. P., and Thedieck, K. (2016) A systems study reveals concurrent activation of AMPK and mTOR by amino acids. Nature communications 7, 13254

34. Cooper, J. M., Ou, Y. H., McMillan, E. A., Vaden, R. M., Zaman, A., Bodemann, B. O., Makkar, G., Posner, B. A., and White, M. A. (2017) TBK1 Provides Context-Selective Support of the Activated AKT/mTOR Pathway in Lung Cancer. Cancer Res 77, 5077-5094

35. Zhu, L., Li, Y., Xie, X., Zhou, X., Gu, M., Jie, Z., Ko, C. J., Gao, T., Hernandez, B. E., Cheng, X., and Sun, S. C. (2019) TBKBP1 and TBK1 form a growth factor signalling axis mediating immunosuppression and tumourigenesis. Nat Cell Biol 21, 1604-1614

36. White, K. A., Grillo-Hill, B. K., and Barber, D. L. (2017) Cancer cell behaviors mediated by dysregulated $\mathrm{pH}$ dynamics at a glance. J Cell Sci 130, 663-669

37. Liu, Y., White, K. A., and Barber, D. L. (2020) Intracellular pH Regulates Cancer and Stem Cell Behaviors: A Protein Dynamics Perspective. Front Oncol 10, 1401

38. Czowski, B. J., Romero-Moreno, R., Trull, K. J., and White, K. A. (2020) Cancer and pH Dynamics: Transcriptional Regulation, Proteostasis, and the Need for New Molecular Tools. Cancers (Basel) 12

39. Sarbassov, D. D., Guertin, D. A., Ali, S. M., and Sabatini, D. M. (2005) Phosphorylation and regulation of Akt/PKB by the rictor-mTOR complex. Science 307, 1098-1101

40. Lamming, D. W., Ye, L., Katajisto, P., Goncalves, M. D., Saitoh, M., Stevens, D. M., Davis, J. G., Salmon, A. B., Richardson, A., Ahima, R. S., Guertin, D. A., Sabatini, D. M., and Baur, J. A. (2012) Rapamycin-induced insulin resistance is mediated by mTORC2 loss and uncoupled from longevity. Science 335, 1638-1643

41. Hardie, D. G., Schaffer, B. E., and Brunet, A. (2016) AMPK: An Energy-Sensing Pathway with Multiple Inputs and Outputs. Trends Cell Biol 26, 190-201 
bioRxiv preprint doi: https://doi.org/10.1101/2021.05.13.444090; this version posted May 13, 2021. The copyright holder for this preprint (which was not certified by peer review) is the author/funder, who has granted bioRxiv a license to display the preprint in perpetuity. It is made available under aCC-BY-NC-ND 4.0 International license.

42. Garcia, D., and Shaw, R. J. (2017) AMPK: Mechanisms of Cellular Energy Sensing and Restoration of Metabolic Balance. Mol Cell 66, 789-800

43. Kilic, A., Velic, A., De Windt, L. J., Fabritz, L., Voss, M., Mitko, D., Zwiener, M., Baba, H. A., van Eickels, M., Schlatter, E., and Kuhn, M. (2005) Enhanced activity of the myocardial $\mathrm{Na}+/ \mathrm{H}+$ exchanger NHE-1 contributes to cardiac remodeling in atrial natriuretic peptide receptor-deficient mice. Circulation 112, 2307-2317

44. Persi, E., Duran-Frigola, M., Damaghi, M., Roush, W. R., Aloy, P., Cleveland, J. L., Gillies, R. J., and Ruppin, E. (2018) Systems analysis of intracellular $\mathrm{pH}$ vulnerabilities for cancer therapy. Nature communications 9, 2997

45. Harguindey, S., Arranz, J. L., Polo Orozco, J. D., Rauch, C., Fais, S., Cardone, R. A., and Reshkin, S. J. (2013) Cariporide and other new and powerful NHE1 inhibitors as potentially selective anticancer drugs--an integral molecular/biochemical/metabolic/clinical approach after one hundred years of cancer research. J Transl Med 11, 282

46. White, K. A., Kisor, K., and Barber, D. L. (2019) Intracellular pH dynamics and charge-changing somatic mutations in cancer. Cancer Metastasis Rev 38, 17-24

47. Genders, A. J., Martin, S. D., McGee, S. L., and Bishop, D. J. (2019) A physiological drop in pH decreases mitochondrial respiration, and HDAC and Akt signaling, in L6 myocytes. Am J Physiol Cell Physiol 316, C404-C414

48. Michl, J., Park, K. C., and Swietach, P. (2019) Evidence-based guidelines for controlling $\mathrm{pH}$ in mammalian live-cell culture systems. Commun Biol 2, 144

49. Talapatra, S., and Thompson, C. B. (2001) Growth factor signaling in cell survival: implications for cancer treatment. J Pharmacol Exp Ther 298, 873-878

50. White, K. A., Ruiz, D. G., Szpiech, Z. A., Strauli, N. B., Hernandez, R. D., Jacobson, M. P., and Barber, D. L. (2017) Cancer-associated arginine-to-histidine mutations confer a gain in $\mathrm{pH}$ sensing to mutant proteins. Sci Signal 10

51. Vercoulen, Y., Kondo, Y., Iwig, J. S., Janssen, A. B., White, K. A., Amini, M., Barber, D. L., Kuriyan, J., and Roose, J. P. (2017) A Histidine pH sensor regulates activation of the Ras-specific guanine nucleotide exchange factor RasGRP1. Elife 6

52. White, K. A., Grillo-Hill, B. K., Esquivel, M., Peralta, J., Bui, V. N., Chire, I., and Barber, D. L. (2018) beta-Catenin is a $\mathrm{pH}$ sensor with decreased stability at higher intracellular $\mathrm{pH}$. J Cell Biol 217, 3965-3976

53. Grillo-Hill, B. K., and White, K. A. (2019) Oncogenic beta-catenin mutations evade pH-regulated degradation. Mol Cell Oncol 6, 1554470

54. Grillo-Hill, B. K., Choi, C., Jimenez-Vidal, M., and Barber, D. L. (2015) Increased H(+) efflux is sufficient to induce dysplasia and necessary for viability with oncogene expression. Elife 4

55. Gwinn, D. M., Shackelford, D. B., Egan, D. F., Mihaylova, M. M., Mery, A., Vasquez, D. S., Turk, B. E., and Shaw, R. J. (2008) AMPK phosphorylation of raptor mediates a metabolic checkpoint. Mol Cell 30, 214-226

56. Inoki, K., Ouyang, H., Zhu, T., Lindvall, C., Wang, Y., Zhang, X., Yang, Q., Bennett, C., Harada, Y., Stankunas, K., Wang, C. Y., He, X., MacDougald, O. A., You, M., Williams, B. O., and Guan, K. L. (2006) TSC2 integrates Wnt and energy signals via a coordinated phosphorylation by AMPK and GSK3 to regulate cell growth. Cell 126, 955-968

57. Jeon, S. M., and Hay, N. (2012) The dark face of AMPK as an essential tumor promoter. Cell Logist 2, 197-202

58. Svensson, R. U., and Shaw, R. J. (2012) Cancer metabolism: Tumour friend or foe. Nature 485, 590-591

59. Hardie, D. G. (2013) The LKB1-AMPK pathway-friend or foe in cancer? Cancer Cell 23, 131-132

60. Gonzalez, A., Hall, M. N., Lin, S. C., and Hardie, D. G. (2020) AMPK and TOR: The Yin and Yang of Cellular Nutrient Sensing and Growth Control. Cell Metab 31, 472-492

61. Acosta-Jaquez, H. A., Keller, J. A., Foster, K. G., Ekim, B., Soliman, G. A., Feener, E. P., Ballif, B. A., and Fingar, D. C. (2009) Site-specific mTOR phosphorylation promotes mTORC1-mediated signaling and cell growth. Mol Cell Biol 29, 4308-4324

62. Huang, J., Dibble, C. C., Matsuzaki, M., and Manning, B. D. (2008) The TSC1-TSC2 complex is required for proper activation of mTOR complex 2. Mol Cell Biol 28, 4104-4115 


\section{Figure Legends}

\section{Figure 1: Amino acid stimulation at alkaline but not physiological pH increases mTORC2 and AMPK signaling}

A. MEFs were cultured in complete media (DMEM/ +FBS) (left) or serum starved overnight, $\sim 16 \mathrm{hr}$. (right). They were next amino acid (AA) starved in D-PBS (50 min) with (left) or without (right) dFBS, pre-treated with Torin1 $(\mathrm{T})$, and treated without $(-)$ or with $(+)$ a commercial amino acid solution (AA-sol) (10 min) to $[1 \mathrm{x}]$ or $[5 \mathrm{x}]$ final. Whole cell lysates were immunoblotted as indicated.

B. MEFs were cultured as in A but amino acid (AA) starved in AA-free DMEM and re-fed with DMEM at $\mathrm{pH} 7.3$ or 8.3 lacking (-) or containing (+) AAs (10 min).

C. MEFs were amino acid starved in D-PBS/ dFBS, pre-treated with Torin1 $(T)$, and stimulated with an AA solution at $\mathrm{pH} 10$ or 7.4 (10 min).

Figure 2: Alkaline extracellular $\mathrm{pH}(\mathrm{pHe})$ is sufficient to increase mTORC2 catalytic activity and signaling

A. MEFs in complete media (DMEM/ +FBS) were re-fed with media at $\mathrm{pH} 7.4$ or 8.3 for various times (5$60 \mathrm{~min})$. Whole cell lysates were immunoblotted as indicated.

B. Similar to A, except cells were pre-treated with Torin1 (T). Graph, mean ratio \pm SD of Akt P-S473/ Akt; $\mathrm{n}=4$ independent experiments. ${ }^{* *} p<0.01$ using one-way ANOVA and Tukey's post hoc tests.

C. Rictor was immunoprecipitated (IP) from MEFs that had been serum starved, pre-treated with Torin1 $(\mathrm{T})$, and re-fed with serum-free DMEM at $\mathrm{pH} 7.4$ or 8.3 (10 min) -/+ Torin1. In vitro kinase (IVK) reactions were performed with ATP and His-Akt1 substrate, with Torin1 present in the IVK reaction (lane 3). IVKs and WCLs were immunoblotted as indicated.

D. MEFs in complete media (DMEM/ FBS) were pre-treated with Torin1 (T) and stimulated without (-) or with (+) $\mathrm{NH}_{4} \mathrm{Cl}(5-10$ min.).

E. Similar to A, except cells were pre-treated with cariporide (30 min).

Figure 3: Incubation of cells in media at alkaline $\mathrm{pH}$ or containing $\mathrm{NH} 4 \mathrm{Cl}$ increases intracellular $\mathrm{pH}$ (pHi)

A. MEFs were pre-loaded with cSNARF-1-AM in in serum-free DMEM pH 7.4 (30 min). They were re-fed with DMEM/ FBS pH 7.4 and one image set was acquired (pre-image \#1 pH 7.4). The cells were re-fed again with the same media, and three image sets were acquired at $40 \mathrm{sec}$., $5 \mathrm{~min}$., and $10 \mathrm{~min}$. At this point, the cells were re-fed once more with DMEM/ FBS at pH 7.4, and another image set was acquired (pre-image \#2 $\mathrm{pH}$ 7.4). Next, the cells were re-fed with DMEM pH 8.3, and three image sets were acquired at $40 \mathrm{sec}$., $5 \mathrm{~min}$., and $10 \mathrm{~min}$. Ratiometric $(580: 640 \mathrm{~nm})$ pseudo-colored images are shown for each treatment condition. Scale bars in the ratiometric images are pseudo-colored between values of 0 (violet) and 2.0 (red). Graph, quantitation of ratiometric images, $n=100$ cells from 4 fields ( 25 cells/field) $+/-$ SD. ${ }^{* *} p<.01$ using one-way ANOVA and Tukey's post hoc tests.

B. MEFs were loaded with cSNARF-1-AM and treated as in A, except image sets were acquired from cells incubated in DMEM /FBS pH 7.4 without (pre-image) or with $\mathrm{N}_{\mathrm{H}} 4 \mathrm{Cl}$ for $40 \mathrm{sec}$., 5 min., or 10 min. Ratiometric (580:640 nm) pseudo-colored images are shown for each treatment condition. Graph, same as above. ${ }^{* *} p<.01$ using ANOVA as above.

Figure 4: AMPK promotes mTORC2 signaling and cell survival in response to alkaline intracellular $\mathrm{pH}(\mathrm{pHi})$

A. Wild type (WT) and AMPK $\alpha 1 / \alpha 2$ double knockout (DKO) MEFs were amino acid starved in D-PBS/ $+\mathrm{dFBS}$ (50 min) and stimulated with an amino acid solution whose $\mathrm{pH}$ had not been adjusted (i.e., $\mathrm{pH}=10$ ) to [5x] final (10 min). Rictor was immunoprecipitated (IP), and IPs and whole cell lysates (WCL) were immunoblotted as indicated.

B. WT and AMPK DKO MEFs were cultured in D-PBS/ +dFBS containing $1 \mathrm{x}$ amino acids (AAs) and re-fed with the same media at $\mathrm{pH} 7.4$ or $9.5(10 \mathrm{~min})$. Note that $\mathrm{pH} 9.5$ is the $\mathrm{pH}$ of D-PBS/ $+\mathrm{dFBS}$ supplemented with $\mathrm{pH} 10 \mathrm{AAs}$ to $1 \mathrm{x}$ final. 
bioRxiv preprint doi: https://doi.org/10.1101/2021.05.13.444090; this version posted May 13, 2021. The copyright holder for this preprint (which was not certified by peer review) is the author/funder, who has granted bioRxiv a license to display the preprint in perpetuity. It is made available under aCC-BY-NC-ND 4.0 International license.

C. WT and AMPK DKO MEFs in complete media (DMEM/ +FBS) were re-fed with the same media at various $\mathrm{pH}$ values, 7.4-8.3 (10 $\mathrm{min})$.

D. WT MEFs cultured in DMEM complete media (CM) (DMEM/ +FBS) or serum-free media (SFM) for 16 hr were re-fed with $\mathrm{CM}$ at $\mathrm{pH} 7.4$ or SFM pH 7.4 or 7.8 without or with Torin1 ( $\mathrm{T}$ ) for an additional $3 \mathrm{hr}$. (19 hrs. total). Graph, mean ratio $\pm \mathrm{SD}$ of $\mathrm{cParp} /$ tubulin and cCasp3/ tubulin. $\mathrm{n}=4$ experiments. ${ }^{*} p<0.05$, ${ }^{* *}$ $p<0.01$ using one-way ANOVA and Tukey's post hoc tests.

E. WT and AMPK $\alpha 1 / \alpha 2$ DKO MEFs were treated as in D. Graph, mean ratio \pm SD of cParp / tubulin. $n=5$ experiments. ${ }^{*} p<0.05,{ }^{* *} p<0.01$ using ANOVA as above. 
bioRxiv preprint doi: https://doi.org/10.1101/2021.05.13.444090; this version posted May 13, 2021. The copyright holder for this preprint (which

was not certified by peer review) is the author/funder, who has granted bioRxiv a license to display the preprint in perpetuity. It is made available under aCC-BY-NC-ND 4.0 International license.

\section{Supplementary Information}

\section{Supplemental Experimental Procedures}

\section{Materials}

General chemicals were from Thermo Fisher Scientific or Sigma Aldrich. NP40, Brij35, and CHAPS detergents were from Pierce; cOmplete Protease Inhibitor Cocktail (EDTA-free) tablets were from Millipore Sigma (\#11836170001); protein A-Sepharose CL-4B was from Sigma-Aldrich (\#17-0780-01); Immobilon$P$ polyvinylidene difluoride (PVDF) membrane $(0.45 \mu \mathrm{M})$ was from Millipore; reagents for enhanced chemiluminescence (ECL) were from Alkali Scientific (Bright Star \#XR92) or Advansta (WesternBright Sirius HRP substrate); $\mathrm{NH}_{4} \mathrm{Cl}$ was from Fisher (\#A661); PageRuler and PageRuler Plus prestained protein ladders were from Thermo Fisher (\#26617; 26619).

\section{Antibodies}

The following antibodies were from Cell Signaling Technology (CST): AMPK $\alpha$ P-T172 (\#4188); panAMPKa (\#2532); Akt P-S473 (\#4060); Akt P-T308 (\#4056); Akt (\#9272); mTOR (\#2972); raptor P-S792 (\#2083); raptor (\#2280); S6K1 P-T389 (\#9234); ACC P-S79 (\#3661); ACC (\#3676); Bad P-S136 (\#4366); cleaved caspase 3 (\#9664); cleaved PARP (\#9544); $\alpha$-tubulin (\#2144); mTOR P-S2481 was from Millipore (\#09-343). The following custom polyclonal anti-peptide antibodies were generated by us with the aid of Covance, as described previously (61): mTOR P- S1261 (amino acids 1256-1266; rat); rictor (amino acids 6-20; human); and S6K1 (amino acids 485-502; rat $70 \mathrm{kDa}$ isoform). Donkey anti-rabbitHRP secondary antibody was from Jackson (\#711-095-152).

\section{Drug treatments, cell lysis, immunoprecipitation, and western blotting}

Cells were pre-treated with Torin1 [100 nM] (30 min.) (shared by D. Sabatini, MIT and Whitehead Institute, Boston, MA) or cariporide [10 $\mu \mathrm{M}$ ] (30 min.) (Sigma \#SML1360) prior to lysis. Unless otherwise indicated, cells were washed $2 x$ in PBS and lysed in buffer containing NP-40 [0.5\%] and Brij35 [0.1\%], as described (61). Lysates were incubated on ice (15 min.) and then spun at 13,200 rpm (5 min.) at $4^{\circ} \mathrm{C}$. Post-nuclear supernatants were normalized for protein levels by Bradford assay. For immunoprecipitation, whole cell lysates were incubated with antibodies for $2 \mathrm{hr}$. at $4^{\circ} \mathrm{C}$ and Protein A-Sepharose beads for $1 \mathrm{hr}$. Beads were washed three times in lysis buffer and resuspended in 1x sample buffer. Samples were resolved on SDS-PAGE and transferred to PVDF membranes in Towbin transfer buffer containing $0.02 \%$ SDS. Western blotting was performed by blocking PVDF membranes in Tris-buffered saline (TBS) pH 7.5 with $0.1 \%$ Tween-20 (TBST) containing 3\% non-fat dry milk, as described, and incubating the membranes in TBST/ BSA $(2 \%)$ containing primary or secondary HRP antibodies. Blots were developed by ECL and detected digitally with a Chemi-Doc-It System (UVP).

\section{mTORC2 in vitro kinase assays}

mTORC2 in vitro kinase (IVK) assays were performed, as described $(25,62)$. Briefly, serum starved MEFs were re-fed with DMEM pH 7.4 or $\mathrm{pH} 8.3$ and lysed in buffer containing CHAPS [0.3\%]. Rictor was immunoprecipitated from a near confluent $10 \mathrm{~cm}$ plate and incubated with ATP [250 $\mu \mathrm{M}]$ and recombinant His-Akt1 [100 ng/reaction] (Millipore \#14-279) in $15 \mu$ l kinase buffer (25 mM HEPES; 100 mM potassium acetate; $1 \mathrm{mM} \mathrm{MgCl} 2$ ) at $30^{\circ} \mathrm{C}$ for $30 \mathrm{~min}$. and stopped by addition of sample buffer followed by incubation at $95^{\circ} \mathrm{C}$ for $10 \mathrm{~min}$.

\section{Image editing}

Adobe Photoshop was used for preparation of western blot images, using only levels, brightness, and/or contrast equivalently over the entire image. All presented images reflect the raw images.

\section{Statistical analysis}

Fiji was used to quantitate ECL western blot signals. Results are presented as mean \pm SD. Significance of the difference between two measurements was determined by Student's $t$ test. Multiple comparisons were analyzed for significance using one-way ANOVA followed by pairwise Tukey's post hoc tests. Values 
of $p<0.05$ were considered significant. All experiments were performed at least three times, if not more, unless indicated otherwise in the figure legend.

\section{Supplementary Figure Legends}

Supplementary Figure 1: Activation of mTORC2 signaling by alkaline extracellular pH (pHe) in C2C12 myoblasts (related to figure 1)

S1A. C2C12 cells were serum and amino acid starved overnight $(\sim 16 \mathrm{hr})$ in HBSS and stimulated with an acid solution at $\mathrm{pH} 7.4$ or 10 to $1 \mathrm{x}$ final $(10 \mathrm{~min})$. Whole cell lysates were immunoblotted as indicated.

S1B. C2C12 cells were serum starved overnight in DMEM ( 16 hr.), shifted to amino acid-free DMEM lacking FBS (50 min), and then stimulated with an amino acid solution at pH 7.4 or 10 to $1 \times$ final (10 min).

Supplementary Figure 2 (related to figure 2)

S2A and S2B. Alkaline extracellular $\mathrm{pH}(\mathrm{pHe})$ increases mTORC2 signaling in HEK293T cells: S2A, HEK293T cells were re-fed with complete media (DMEM/ FBS) (30 min) and then re-fed again with media at $\mathrm{pH} 7.4$ or 8.3 for various times $(0-60 \mathrm{~min})$. Whole cell lysates were immunoblotted as indicated. S2B, HEK293T cells were pre-treated without or with Torin1 (T) or cariporide (C), and re-fed with complete media (DMEM/ FBS) at $\mathrm{pH} 7.4$ or 8.3 (15 min) without or with drugs.

S2C. Alkaline pHe dose response in MEFs. MEFs in complete media (DMEM/ FBS) were re-fed with media at various $\mathrm{pH}$ values $(\mathrm{pH}$ 7.4-9.0) (10 min). 


\section{Figure 2}

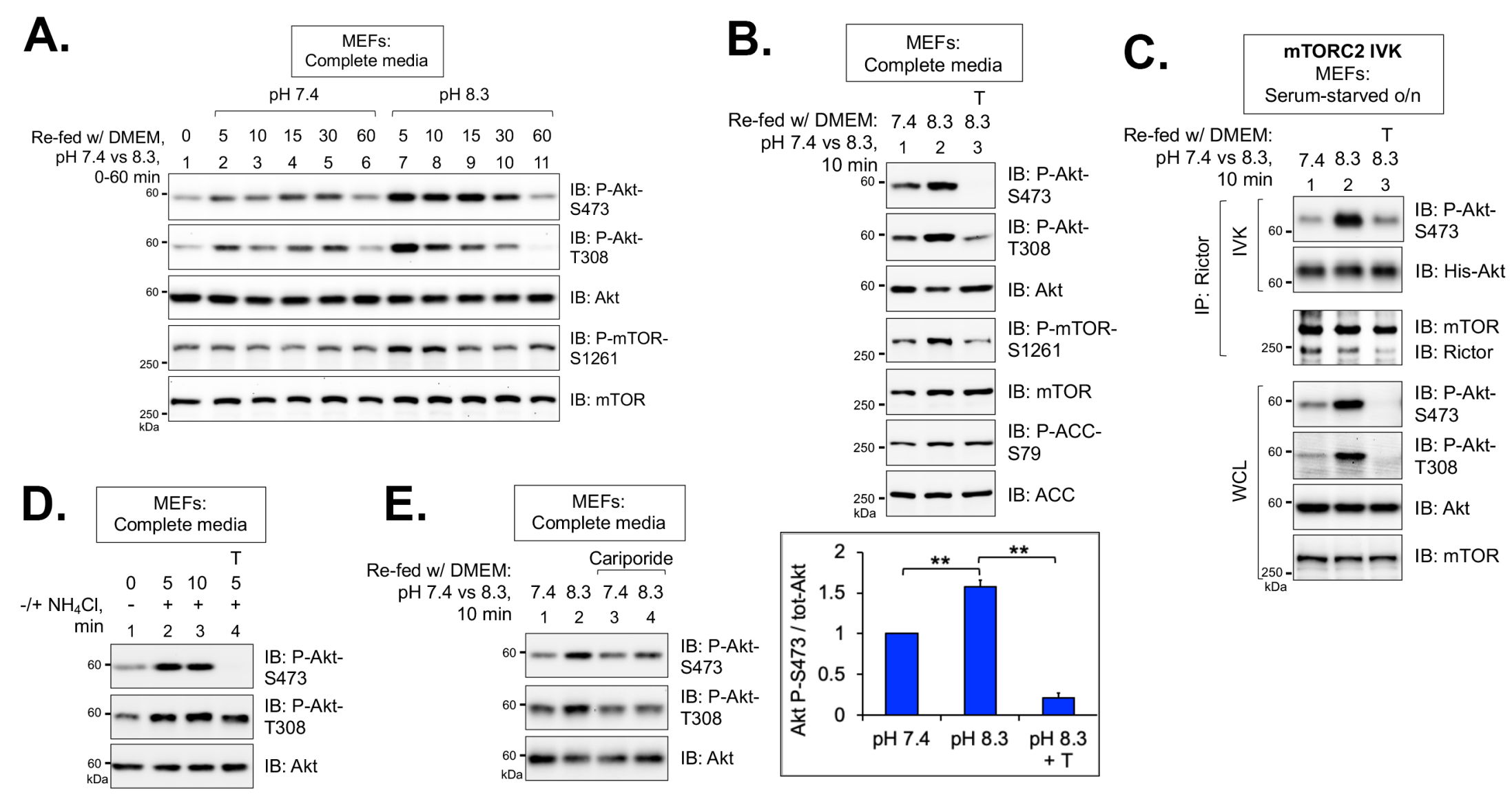


Figure 3

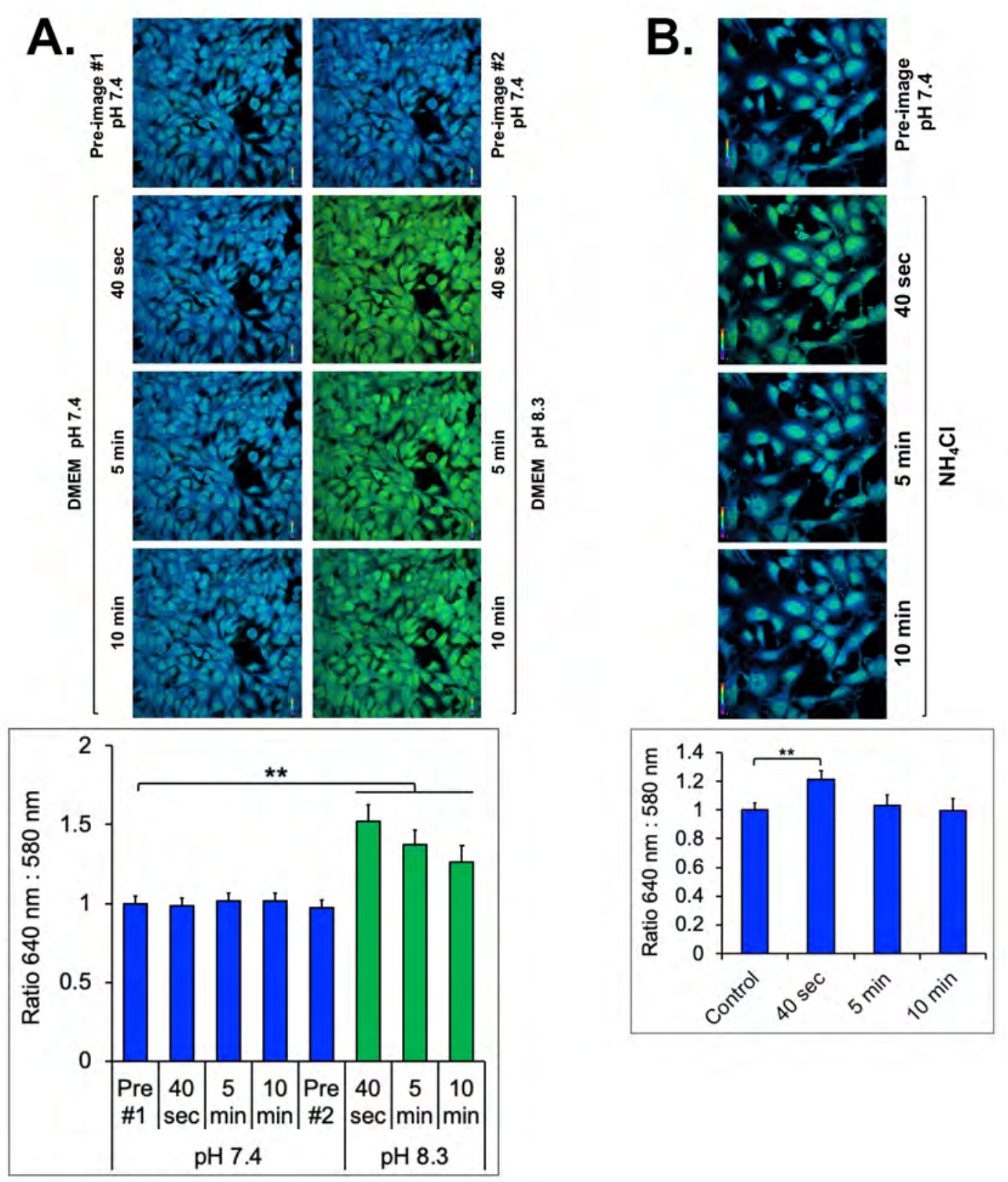




\section{Figure 4}
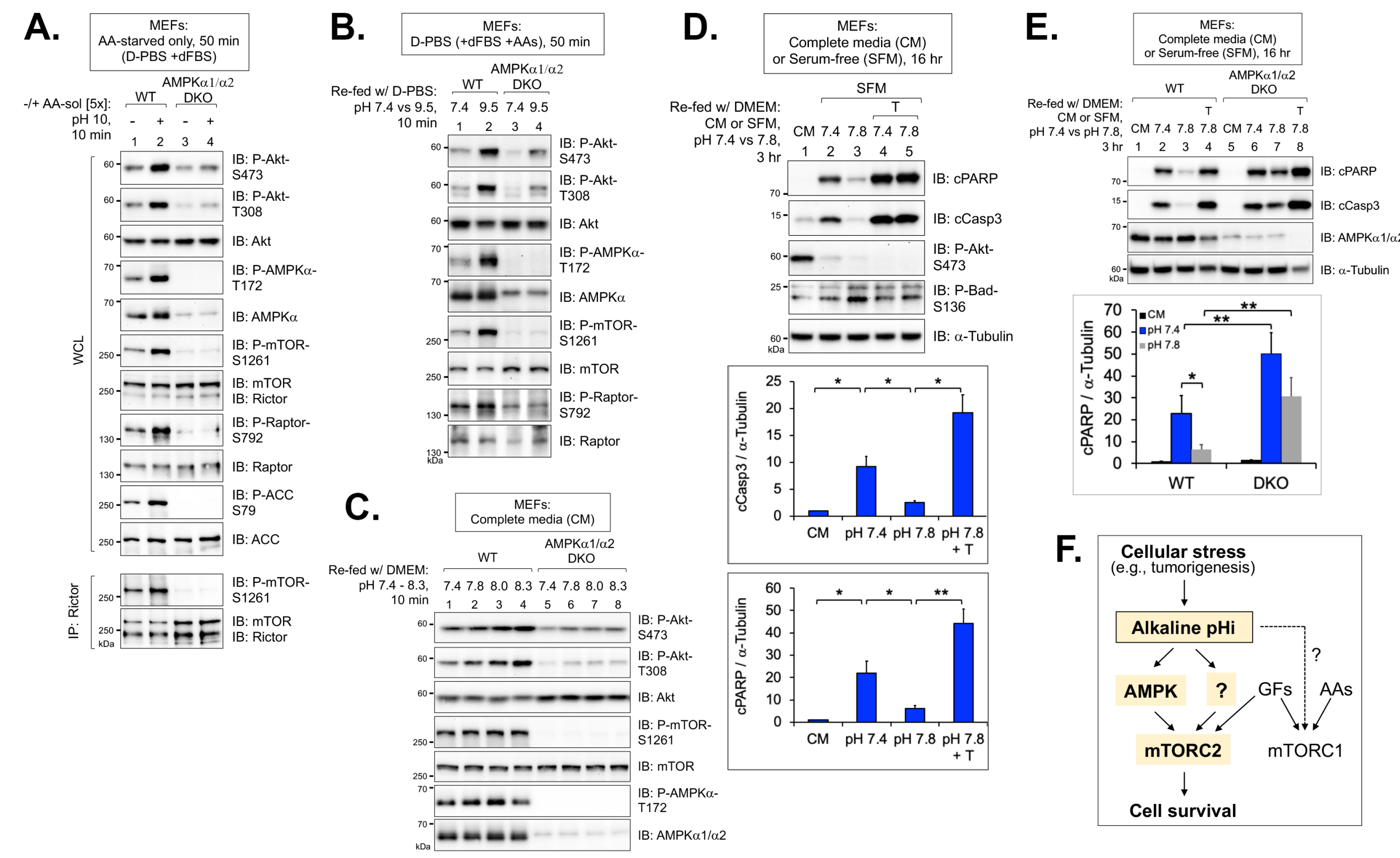

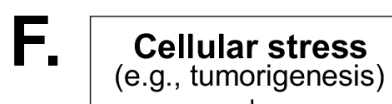

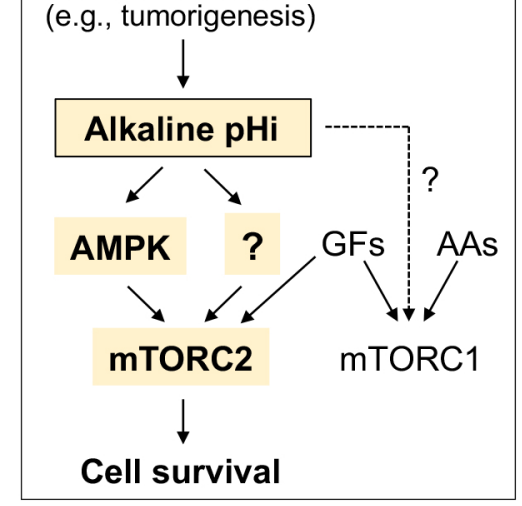




\section{Supplementary Figure S1 (related to Figure 1)}
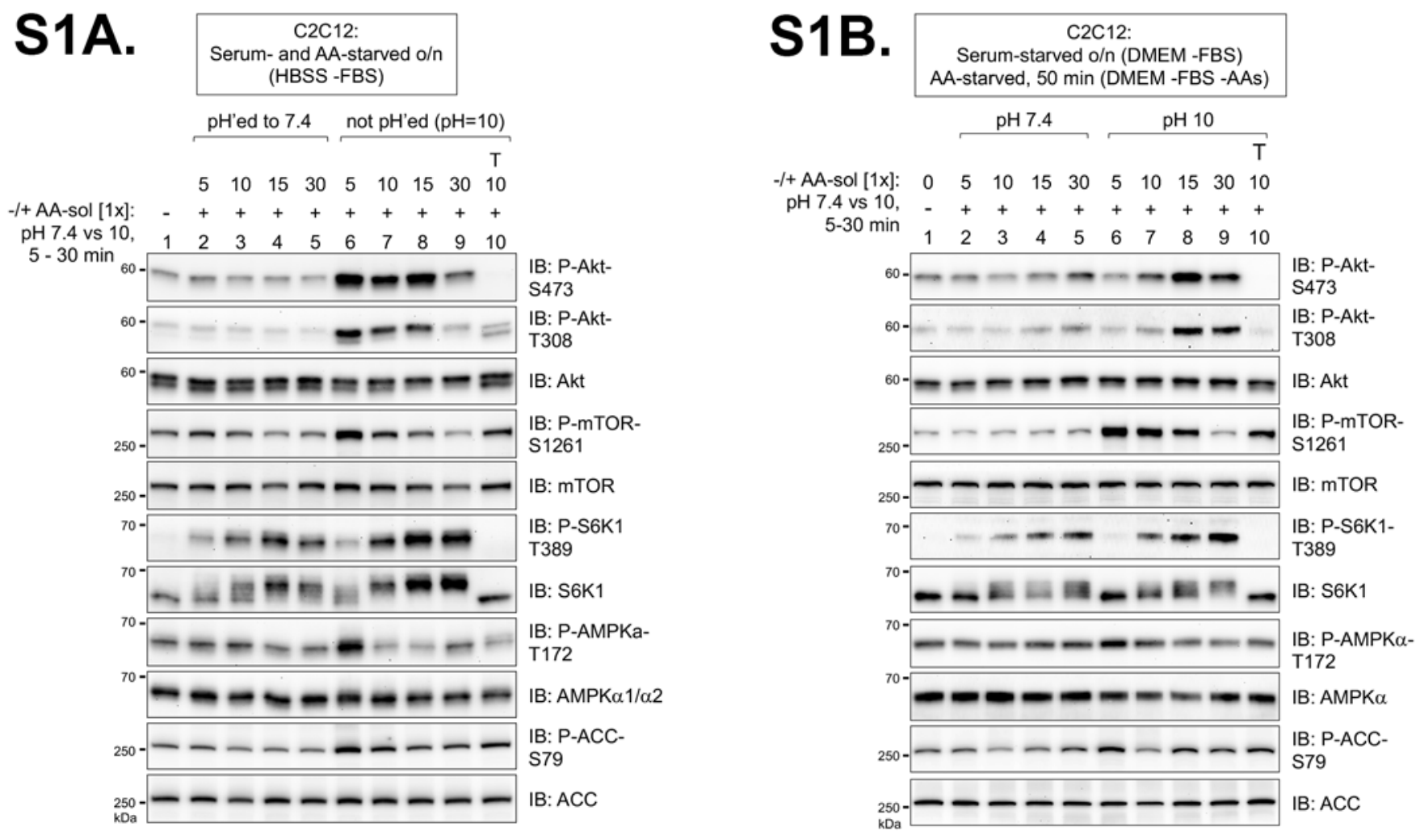


\section{Supplementary Figure S2}

(related to Figure 2)
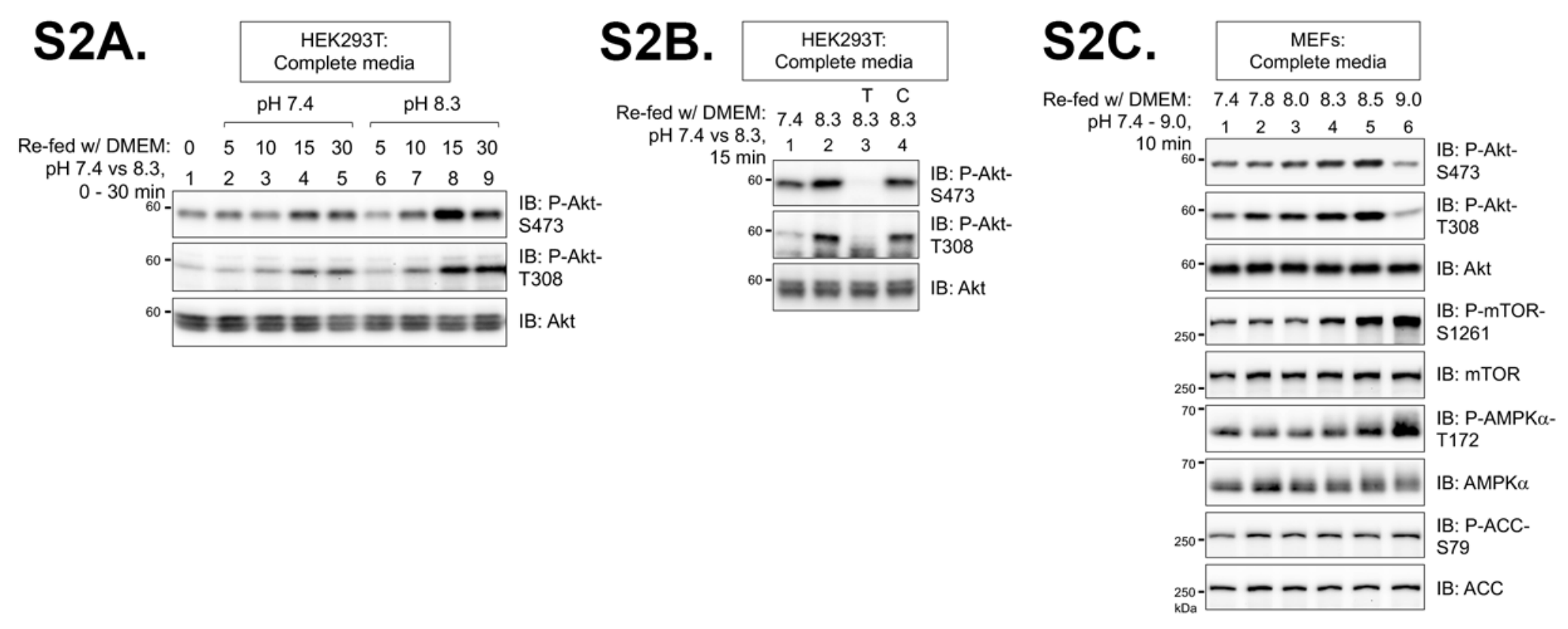


\section{Supplementary Figure S3 \\ (related to Figure 4)}

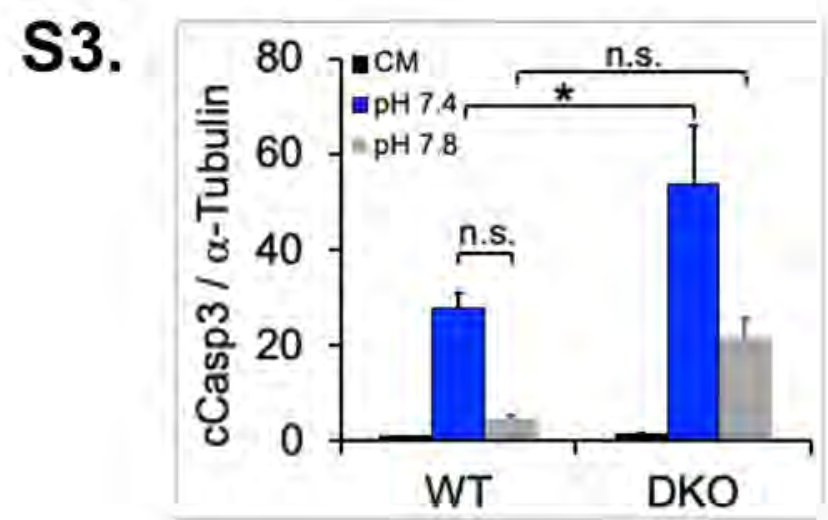

